\title{
Multiphysics Analysis of CFRP Charpy Tests by varying Temperatures
}

\section{Z Andleeb ${ }^{1 *}$, C Strand ${ }^{2}$, S Malik', G Hussain', H Khawaja ${ }^{2}$, G Boiger ${ }^{3}$, M Moatamedi,5}

1. GIKI, Ghulam Ishaq Khan Institute of Technology, Topi, Pakistan

2. UiT, The Arctic University of Norway, Tromsø, Norway

3. ZHAW, Zurich University of Applied Sciences, Switzerland

4. OSLOMET, Oslo Metropolitan University, Norway

5. AGU, Al Ghurair University, Dubai, UAE

\begin{abstract}
Carbon Fiber Reinforced Polymer (CFRP) composites have emerged as a major class of structural materials that have a significant potential use as a substitute for metals in aerospace, marine, automotive, and architecture due to their higher-strength-to-weight-ratio. CFRP is well suited for various applications, but their mechanical properties such as 'low-velocity impact resistance' are not well studied. In this study, the low-velocity impact resistance of CFRP woven composite was investigated with the help of Charpy impact tests. The CFRP samples were tested at room temperature $\left(22^{\circ} \mathrm{C}\right)$ and at low temperature $\left(-20^{\circ} \mathrm{C}\right)$. The experimental results indicated about $10 \%$ drop in energy-absorbing capability of CFRP samples at low temperatures in comparison to room temperature. The experimental results obtained for the room temperature were validated through finite element simulations using ANSYS ${ }^{\circledR}$ Workbench Explicit Dynamics. The mesh sensitivity analysis was performed to improve the accuracy of the finite element model. The numerical results helped to narrow down on the CFRP material properties that changed with temperature drop. It was found at $-20^{\circ} \mathrm{C}$, orthotropic Elasticity (Young's moduli in three mutually perpendicular directions) increases for CFRP woven composite as compared to room temperature $\left(22^{\circ} \mathrm{C}\right)$, however the CFRP become brittle and there is a significant drop in their toughness. The current outcomes are useful for applications using CFRP under impact loading at low temperatures.
\end{abstract}

\section{INTRODUCTION}

Carbon Fiber Reinforced Polymer (CFRP) has emerged as a promising material in automotive aerospace and structural engineering due to higher specific strength, specific rigidity, and corrosion resistance as well as its lighter weight properties compared to those of metal materials [1,2]. Composite materials consist of two parts: the matrix and reinforcement. In CFRP, the reinforcement is carbon fiber, which provides the strength and rigidity. The matrix consists of a polymer resin, such as epoxy, to bind the reinforcements together. Since CFRP consists of two distinct elements, the material properties depend on these two elements according to the rule and inverse rule of mixtures.

*Corresponding Author: gme1808@giki.edu.pk 
It should be noted that Young's Modulus changes with direction along the material. Therefore, CFRP is considered an anisotropic material [3, 4]. CFRP unlike metals have complex fracture mechanisms such as fiber fracture, fiber separation from interface, and delamination that makes fracture toughness of CFRP a complex phenomenon. Despite many superior properties of CFRP over metals they are susceptible to damages caused by low velocity impact during service that reduces their performance to a great extent [5-12]. Therefore, it is very crucial to understand the variation in fracture toughness of CFRP when subjected to low velocity impact at various temperatures.

Charpy impact test is a standardized testing method to determine fracture toughness of a material [13]. This high strain-rate test as shown in Figure 1, measures the material's ability to absorb energy before failure and it is often used as an effective tool to study temperature dependent ductile-brittle behavior. During the Charpy impact test standardized sample material is used to calculate material toughness under specific conditions i.e. mounting, notching and pendulum velocity at impact. A specimen is stroked with a controlled weight pendulum swung from a set height as seen in Figure 1 [14-16]. In general, pendulum impact tests are subject to errors due to kinetic energy and vibrational losses, but these losses are so small that they are negligible $[15,16]$.

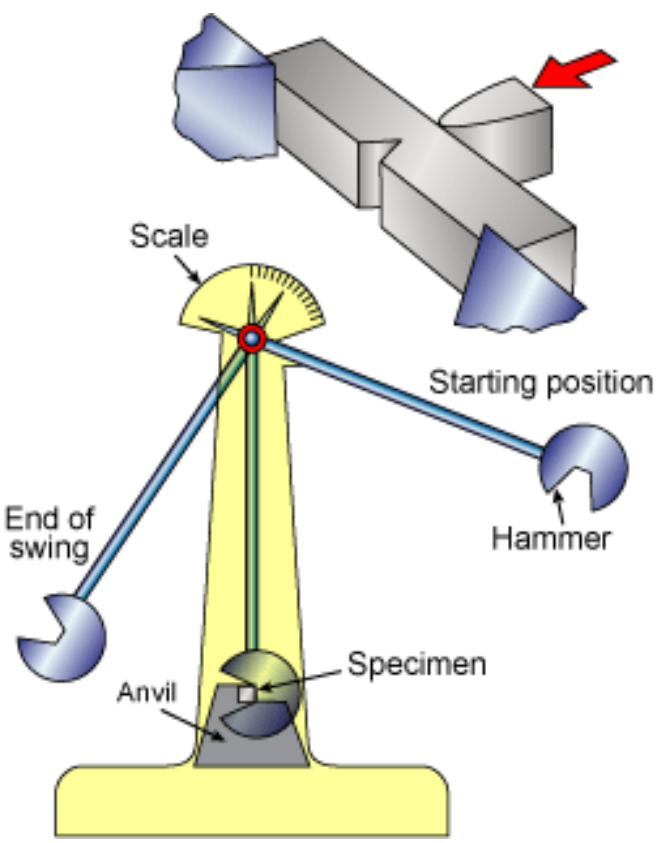

Figure 1: A schematic of the Charpy pendulum impact machine [14].

The fracture toughness is often measured by calculating the area under the stress-strain curve as shown in Figure 2. Brittle materials fracture at low strains and absorb little energy. Conversely, ductile materials fail after significant plastic strain (deformation), absorb more energy, and thus described as tough [17]. 


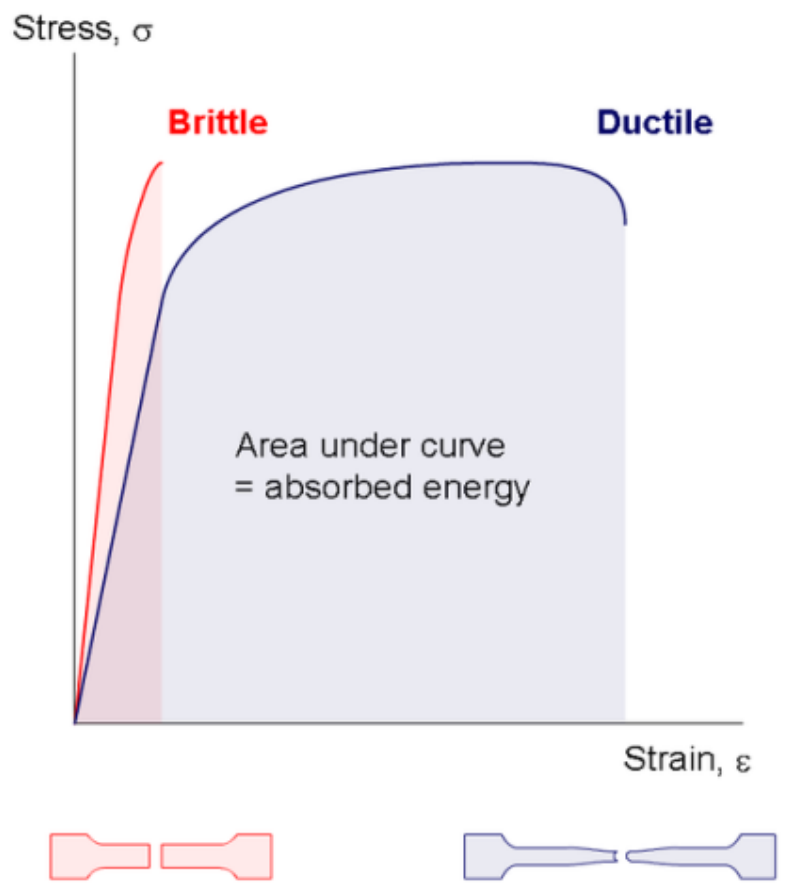

Figure 2: Stress-strain curve of ductile and brittle materials [17].

Modulus of elasticity or Young's modulus is a numerical constant that describes the elastic properties of a material. It explains how much material will stretch or compresses (strain) in relation to the applied stress till the yield point [18]. Stress strain relationship was studied with the help of thermography by Stange et al., $[19,20]$. A 2-D stress analysis technique was also discussed by Khawaja et al. [21]. Every material has a unique value for the elastic modulus.

The two equations for the calculation of the net elastic modulus of woven composite materials takes into account the layout of carbon fibers and proportion of carbon fibers compared to matrix [22].

Rule and inverse rule of mixtures for woven composites [22, 23] are shown in Equations (1-3) as given below. The rule of mixture is stated in Equation (1),

$$
E_{1}=E_{f l} v_{f l}+E_{f t} v_{f t}+F_{m} E_{m} v_{m}
$$

where $E_{f l}$ is the fiber modulus in longitudinal direction, $E_{f t}$ is fiber modulus in transverse direction, $E_{m}$ is matrix modulus, $F_{m}$ is matrix mechanical property retention ratio, $v_{f l}$ is volume fraction of fiber in longitudinal direction, $v_{f t}$ is volume fraction of fiber in transverse direction, and $v_{m}$ is volume fraction of matrix. 
In pseudo isotropic woven composites, the values of Young's moduli in longitudinal (x-direction) and transverse (y-direction) can be assumed to be same as shown in Equation (2),

$$
E_{2}=E_{1}
$$

where $E_{1}$ is composite Young's modulus in x direction and $E_{2}$ is composite Young's modulus in y direction.

Young's modulus can be calculated in z-direction using the inverse rule of mixture as shown in Equation (3),

$$
\frac{1}{E_{3}}=\frac{1}{E_{f t} v_{f}}+\frac{1}{F_{m} E_{m} v_{m}}
$$

where $E_{3}$ is composite Young's modulus in z direction.

Failure strain describes materials ability to elongate before failure [24]. It includes both strains in the elastic and the plastic region. A ductile material has a lower elastic modulus (stiffness) but a larger deformability or failure strain. When a material undergoes changes from ductile to brittle nature due to temperature variation, both stiffness and failure strain values changes considerably to account for the reduction in area under the stress strain curve.

\section{METHODOLOGY}

Charpy impact tests were performed in the Safety Lab and the Process Lab at UiT, The Arctic University of Norway. The cold room in the Safety Lab was used for exposure of the CFRP samples to $-20^{\circ} \mathrm{C}$. Results were recorded for tests performed at room temperature and cold room. By using the rule of mixtures, inverse rule of mixtures and matrix mechanical property retention ratio, stiffness of CFRP sample were calculated for $22^{\circ} \mathrm{C}$ and $-20^{\circ} \mathrm{C}$.

The numerical analyses for the tests were then performed in ANSYS Workbench Explicit Dynamic module [25-27]. By using the value of initial velocity of Charpy hammer as obtained by calculations from experimental results and stiffness values for room temperature, simulations were set up. After setting up the room temperature simulation, stiffness values were changed to cold temperature values and results were matched with the experiments.

\subsection{CFRP test specimen}

Test samples used in this study were from the DragonPlate ${ }^{\circledR}$, manufactured by Allred and Associates Inc., Elbridge, New York [28]. The CFRP samples used were EconomyPlate ${ }^{\mathrm{TM}}$ solid carbon fiber sheet $\sim 5 \mathrm{~mm} \times 304.8 \mathrm{~mm} \times 304.8 \mathrm{~mm}$ [29]. EconomyPlate ${ }^{\mathrm{TM}}$ sheets comprised of orthotropic (non-quasi-isotropic) at $0^{\circ} / 90^{\circ}$ orientation laminates (Figure 3), while maintaining a symmetrical and balanced laminate. EconomyPlate ${ }^{\mathrm{TM}}$ composed entirely of a tough and rigid carbon reinforced epoxy matrix, with textured finish on both sides. Samples were cut into smaller pieces for test purposes (Figure 4). 


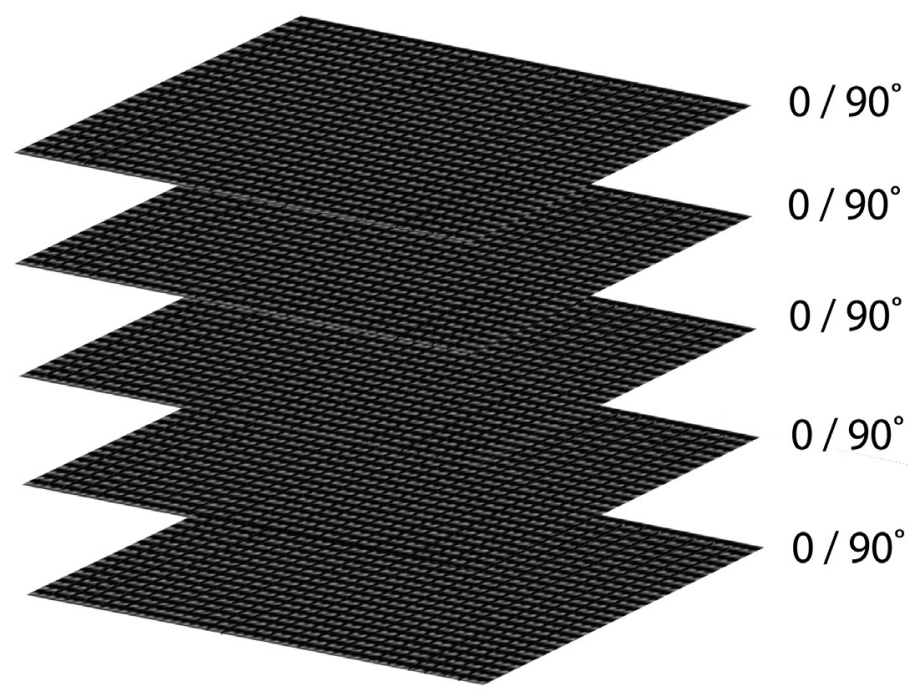

Figure 3: $0^{\circ} / 90^{\circ}$ Orientation Laminate

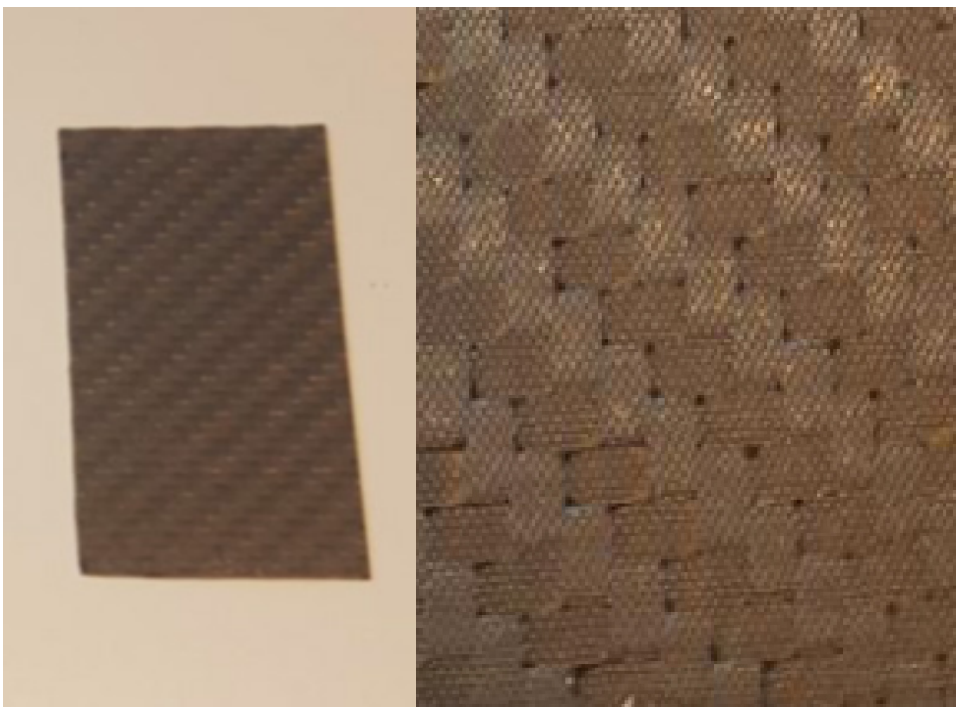

Figure 4: CFRP sheet used in test

The test piece with its geometric variables plays an important role on the values being measured. One of the geometric variables is the span-to-thickness ratio $\left(L_{c} / d\right)$, as seen in Figure 5 . 


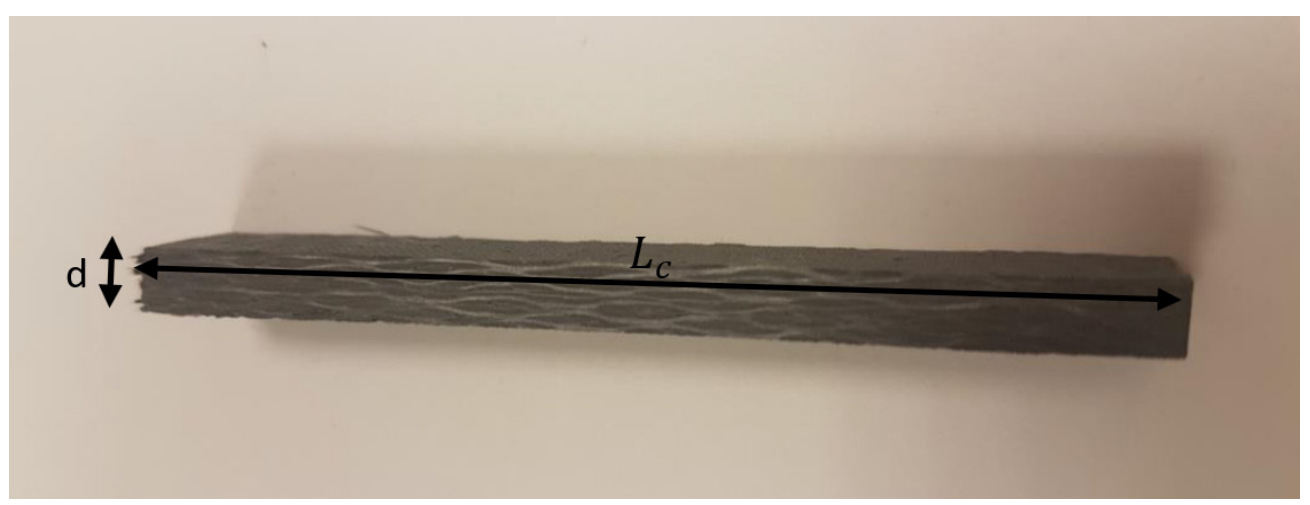

Figure 5: The span-to-thickness ratio $\left(L_{c} / d\right)$ of a test piece of CFRP

According to the recommendation given by Bader and Ellis [30], the span-to-thickness ratio $L_{c} / d$ should be 10 or more for trustworthy results. In this project, samples with predimensioned thickness $d$ of $5 \mathrm{~mm}$ were provided. To meet the recommendations for the ratio $L_{c} / d$, the length $L_{c}$ of the test pieces was adjusted.

By measurements on the Charpy machine intended for the project, in addition to running tests with different lengths, a proper length $L_{c}$ of $60 \mathrm{~mm}$ was found. This gives a span-tothickness ratio $L_{c} / d$ as shown in Equation (4),

$$
\frac{L_{c}}{d}=\frac{60 \mathrm{~mm}}{5 \mathrm{~mm}}=12
$$

where $L_{c} / d$ is span-to-thickness ratio.

\subsection{Charpy test}

The test pieces used for the Charpy impact test were un-notched. Each type of test had 20 test pieces designated to them. This was done to minimize human error in operation with the Charpy pendulum. Following tests were performed:

- Charpy impact test on test pieces at room temperature (about $22^{\circ} \mathrm{C}$ ). The tests were performed on 20 test pieces.

- Charpy impact test on test pieces at cold temperature (about $-20^{\circ} \mathrm{C}$ ). The tests were performed inside the cold room on 20 test pieces, after keeping the samples in the cold temperature for one week to enable the pieces attain the temperature of the cold room.

The Charpy impact-testing machine used in this study is shown in Figure 6. The apparatus consists of a pendulum of known mass and length that is dropped from a known height to impact a specimen of material. The energy transferred to the material can be inferred by comparing the difference in the height of the hammer before and after the fracture (energy absorbed by the fracture event). 


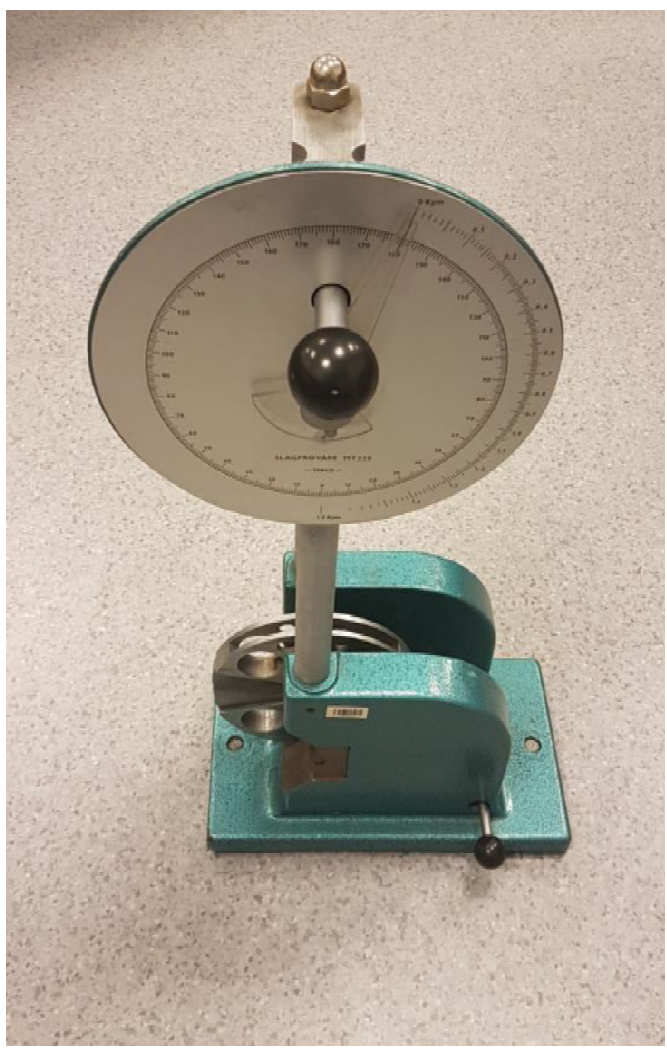

Figure 6: The Charpy testing machine used in this research.

\subsection{Numerical Analysis}

The numerical analyses were performed in ANSYS ${ }^{\circledR}$ Workbench Explicit Dynamics module [25-27]. The material for the Charpy hammer-edge and support blocks was chosen to be Charpy steel from the ANSYS ${ }^{\circledR}$ material library. The material assigned to the CFRP sample was the Epoxy Carbon Woven (230GPa) Wet, with pre-defined parameters in ANSYS ${ }^{2}$, except for stiffness values that were manually entered. As the CFRP sample used in the Charpy impact test was woven so the Young's moduli in $\mathrm{X}$ and $\mathrm{Y}$ direction were calculated by rule of mixtures (as shown in Table 1) to have similar values. The modulus in $\mathrm{Z}$ direction was calculated through inverse rule of mixtures as the $\mathrm{Z}$ direction is transverse to the fiber direction. As the CFRP sample was made of five plies, the resultant stiffness values of the entire lamina were calculated as shown in Table 1.

The geometric model is shown in Figure 7. Symmetry was used on the model in negative $\mathrm{x}$-direction and positive y-direction (as shown in Figure 7(a)) to ease the computational load of the simulation. The dimensions of the CFRP test piece, the Charpy hammer edge and the support points are the same as in the experimental test as shown in Figure 7(b). Initial velocity assigned to the Charpy hammer-edge before impact was $3.87 \mathrm{~m} / \mathrm{s}$ in ANSYS ${ }^{\circ}$ simulation as shown in Figure 8(a). The Charpy machine support blocks were fixed as shown in Figure 8(b) as per the experimental setup. 
Table 1: Calculated values of orthotropic stiffness values from rule and inverse rule of mixtures.

\begin{tabular}{lcc}
\hline & $\begin{array}{c}\boldsymbol{E}_{\mathbf{1}}=\boldsymbol{E}_{\mathbf{2}} \\
\text { for single ply (GPa) }\end{array}$ & $\begin{array}{c}\boldsymbol{E}_{\mathbf{3}} \\
\text { for single ply (GPa) }\end{array}$ \\
\hline Room Temperature $\left(22^{\circ} \mathrm{C}\right)$ & 59.024 & 6.30 \\
Cold Temperature $\left(-20^{\circ} \mathrm{C}\right)$ & 59.334 & 7.01 \\
\hline
\end{tabular}

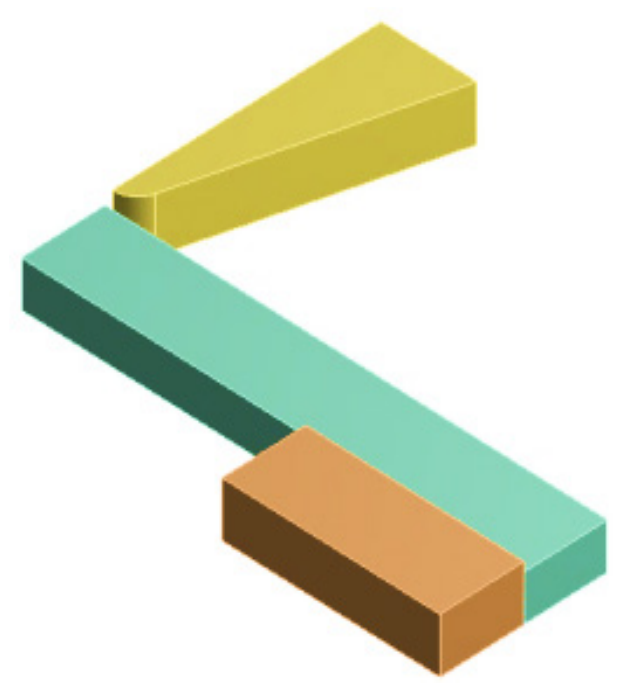

(a) Quarter geometric model

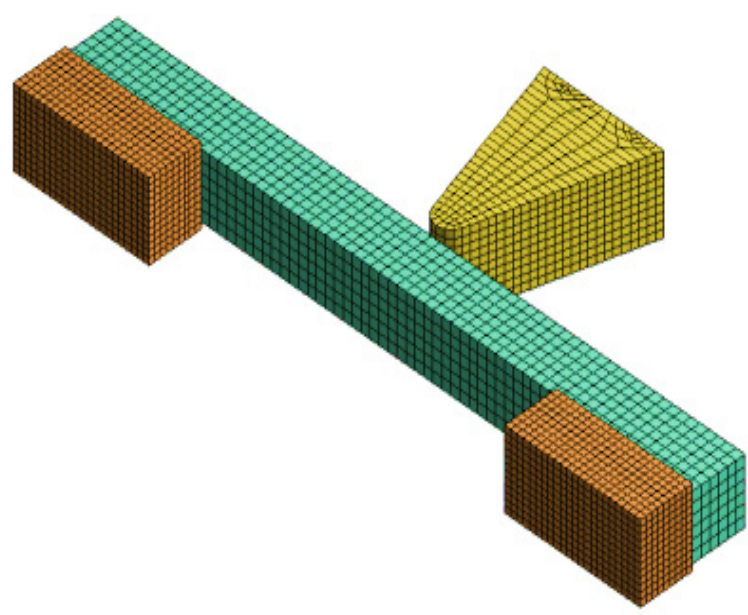

b) Finite element mesh (expanded model)

Figure 7: Charpy hammer-edge and CFRP sample 


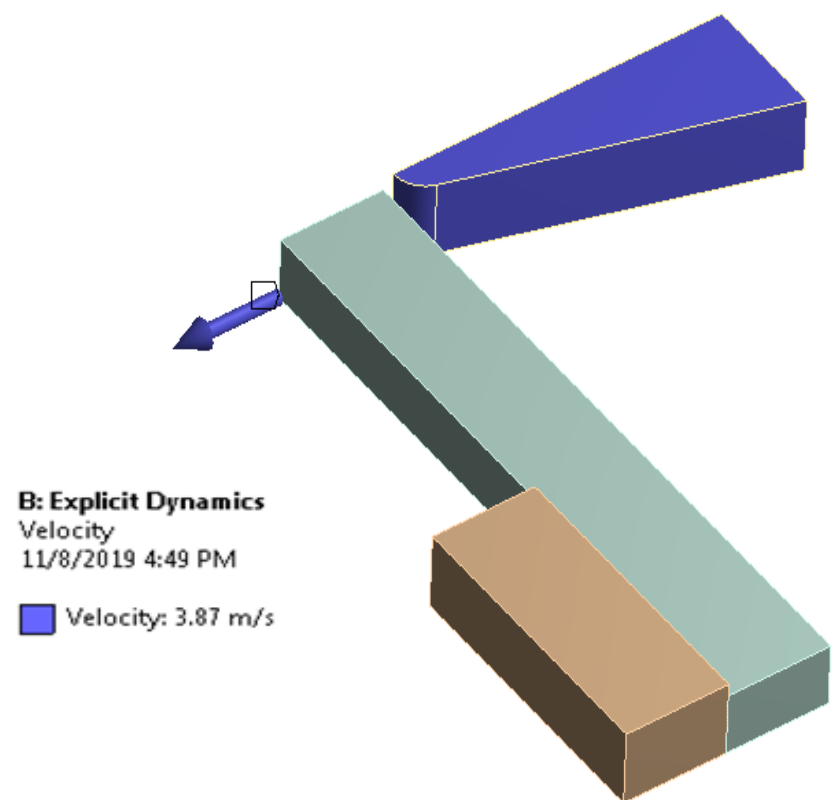

(a) Initial velocity $(3.87 \mathrm{~m} / \mathrm{s})$ specified to the Charpy hammer-edge

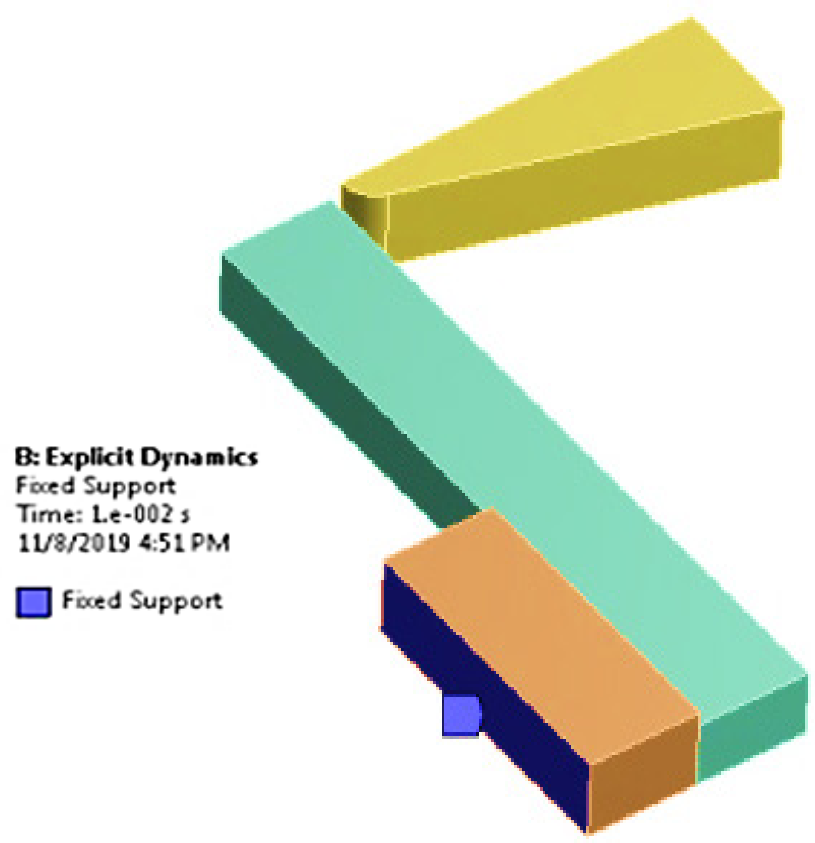

(b) Fixed support block

Figure 8: Initial and boundary conditions 
The Simulation model parameters are shown in Table 2. The body interactions were assigned frictional contacts with static and dynamic coefficient of friction values of 0.83 . Friction coefficients were determined after performing several simulations and gradually increasing the coefficients, the final values are shown in Table 3.

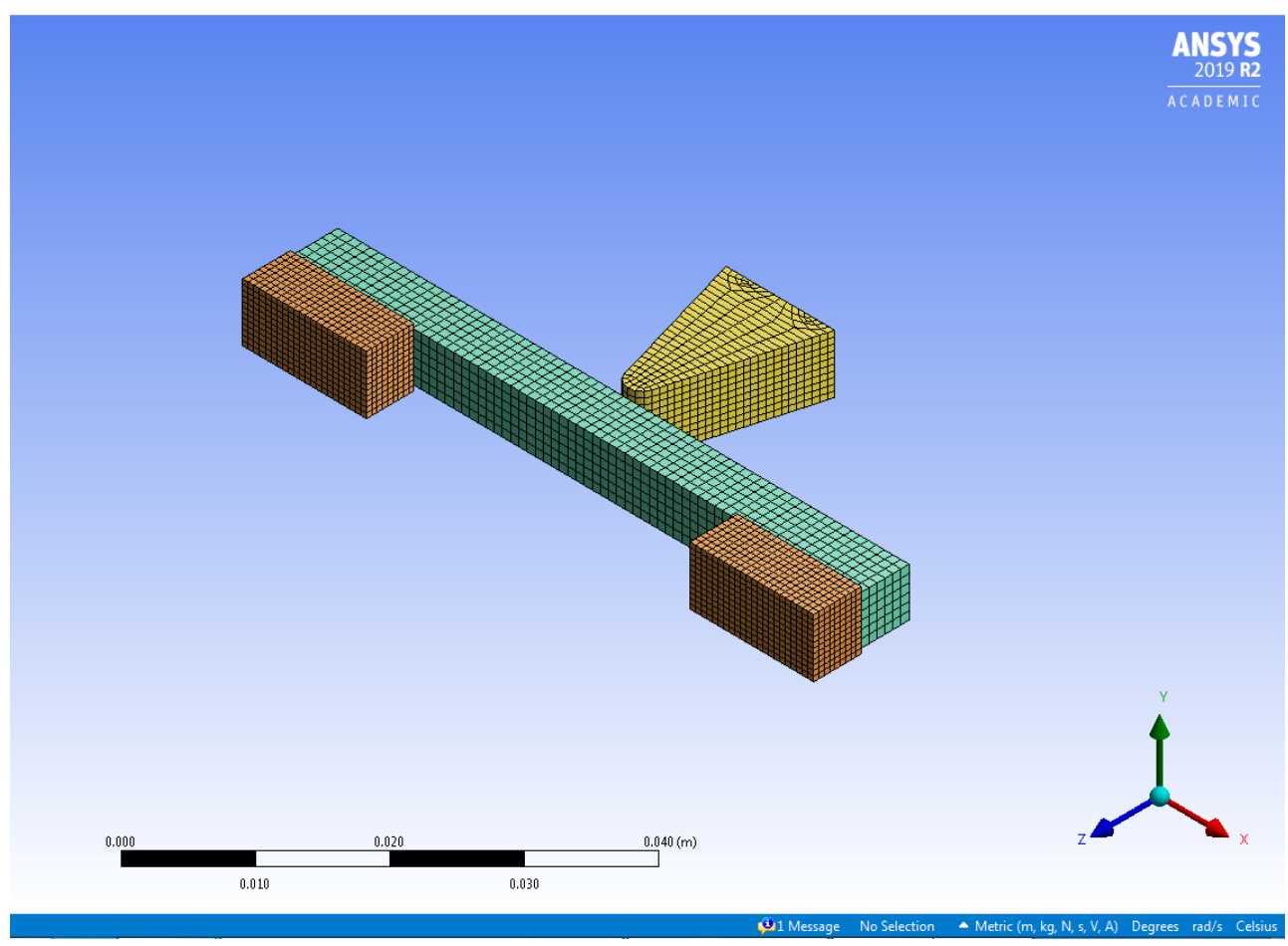

Figure 9: ANSYS® Workbench software-window

Table 2: Simulation model parameters (ANSYS $®$ Explicit Dynamic)

\begin{tabular}{|c|c|c|c|}
\hline \multirow{2}{*}{$\begin{array}{l}\text { Stiffness Behavior } \\
\text { Reference Temperature } \\
\text { Reference Frame } \\
\text { Material Assignments }\end{array}$} & \multicolumn{3}{|c|}{$\begin{array}{c}\text { Flexible } \\
\text { By Environment } \\
\text { Lagrangian }\end{array}$} \\
\hline & Charpy-Steel & $\begin{array}{l}\text { Epoxy Carbon } \\
\text { Woven } \\
(230 G P a) \text { Wet }\end{array}$ & Charpy-Steel \\
\hline Volume & $1.95 \mathrm{e}-007 \mathrm{~m}^{3}$ & $3.75 \mathrm{e}-007 \mathrm{~m}^{3}$ & $1.6397 \mathrm{e}-007 \mathrm{~m}^{3}$ \\
\hline Mass & $0.57907 \mathrm{~kg}$ & $5.4412 \mathrm{e}-004 \mathrm{~kg}$ & $0.48692 \mathrm{~kg}$ \\
\hline Nodes & 1610 & 1008 & 726 \\
\hline Elements & 1188 & 630 & 445 \\
\hline
\end{tabular}

To create a finite element (FE) model, an automated mesh was generated in ANSYS ${ }^{\circledR}$ Workbench. A mesh sensitivity analysis was performed by increasing the number of nodes and elements to see when the solution to the simulation converged. Figure 9 shows the software-window of the explicit dynamic analysis in ANSYS ${ }^{\circledR}$ Workbench. 
Table 3: Body Interactions from ANSYS $®$ simulation

\begin{tabular}{ll}
\hline Object Name & Frictional - Solid to Solid \\
State & Fully Defined \\
\hline Type & Definition \\
Friction Coefficient & Frictional \\
Dynamic Coefficient & 0.83 \\
Decay Constant & 0.83 \\
Scope Mode & 0. \\
\hline
\end{tabular}

\section{RESULTS AND DISCUSSIONS}

\subsection{Experimental Results}

Table 4 illustrates experimental values of the Charpy test as obtained by using CFRP samples at room and cold temperature. Results indicates about $10 \%$ drop in energy absorbing capability of CFRP woven composite in cold room $\left(-20^{\circ} \mathrm{C}\right)$ as compared to room temperature $\left(22^{\circ} \mathrm{C}\right)$

Table 4: Experimental Results

\begin{tabular}{lcccc}
\hline & $\begin{array}{c}\text { Highest } \\
\text { Reading } \\
(\mathbf{N m})\end{array}$ & $\begin{array}{c}\text { Lowest } \\
\text { Reading } \\
(\mathbf{N m})\end{array}$ & $\begin{array}{c}\text { Average } \\
(\mathbf{N m})\end{array}$ & $\begin{array}{c}\text { Standard } \\
\text { deviation } \\
(\mathbf{N m})\end{array}$ \\
\hline Room Temp $\left(22^{\circ} \mathrm{C}\right)$ & 8.34 & 3.83 & 5.89 & 1.34 \\
Cold Temp $\left(-20^{\circ} \mathrm{C}\right)$ & 8.04 & 3.34 & 5.31 & 1.53 \\
\hline
\end{tabular}

From the initial and final energy values of the Charpy test, velocities were calculated by using the mass of the Charpy hammer and standard kinetic energy equation as shown in Table 5 and 6. Calculated velocities are shown in Table 7. Mass of Charpy hammer was found to be equivalent of $1.948 \mathrm{~kg}$. Figure 10 shows the qualitative results of the Charpy test. Room temperature shows ductile failure whereas cold temperature illustrates brittle failure.

Table 5: Room temperature $\left(22^{\circ} \mathrm{C}\right)$ calculations

Energy value recorded from Charpy machine without sample $14.6 \mathrm{~J}$

Energy drop after impact with CFRP sample at room temperature $\left(20^{\circ} \mathrm{C}\right)$

Energy remaining of Charpy hammer

Initial velocity of Charpy edge before impact $=\left[\frac{14.6 \times 2}{\text { mass }}\right]^{-\frac{1}{2}}$

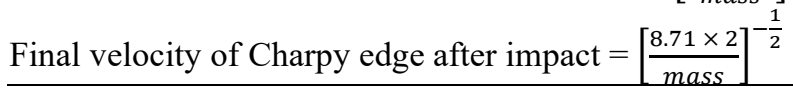

$2.99 \mathrm{~m} / \mathrm{s}$

Table 6: Cold temperature $\left(-20^{\circ} \mathrm{C}\right)$ calculations

Energy value recorded from Charpy machine without sample

Energy drop after impact with CFRP sample at room temperature $\left(20^{\circ} \mathrm{C}\right)$

Energy remaining of Charpy hammer

Initial velocity of Charpy edge before impact $=\left[\frac{14.6 \times 2}{\text { mass }}\right]^{-\frac{1}{2}}$

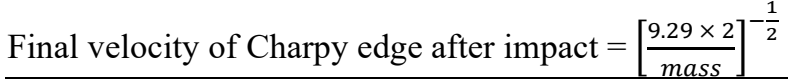


Table 7: Calculated velocities from experimental Results

Initial velocity of Charpy Final velocity of Charpy

hammer edge $(\mathrm{m} / \mathrm{s}) \quad$ hammer edge $(\mathrm{m} / \mathrm{s})$

\begin{tabular}{lcc}
\hline Room Temperature $\left(22^{\circ} \mathrm{C}\right)$ & 3.87 & 2.99 \\
Cold Temperature $\left(-20^{\circ} \mathrm{C}\right)$ & 3.87 & 3.09 \\
Velocity difference & & -0.10 \\
\hline
\end{tabular}

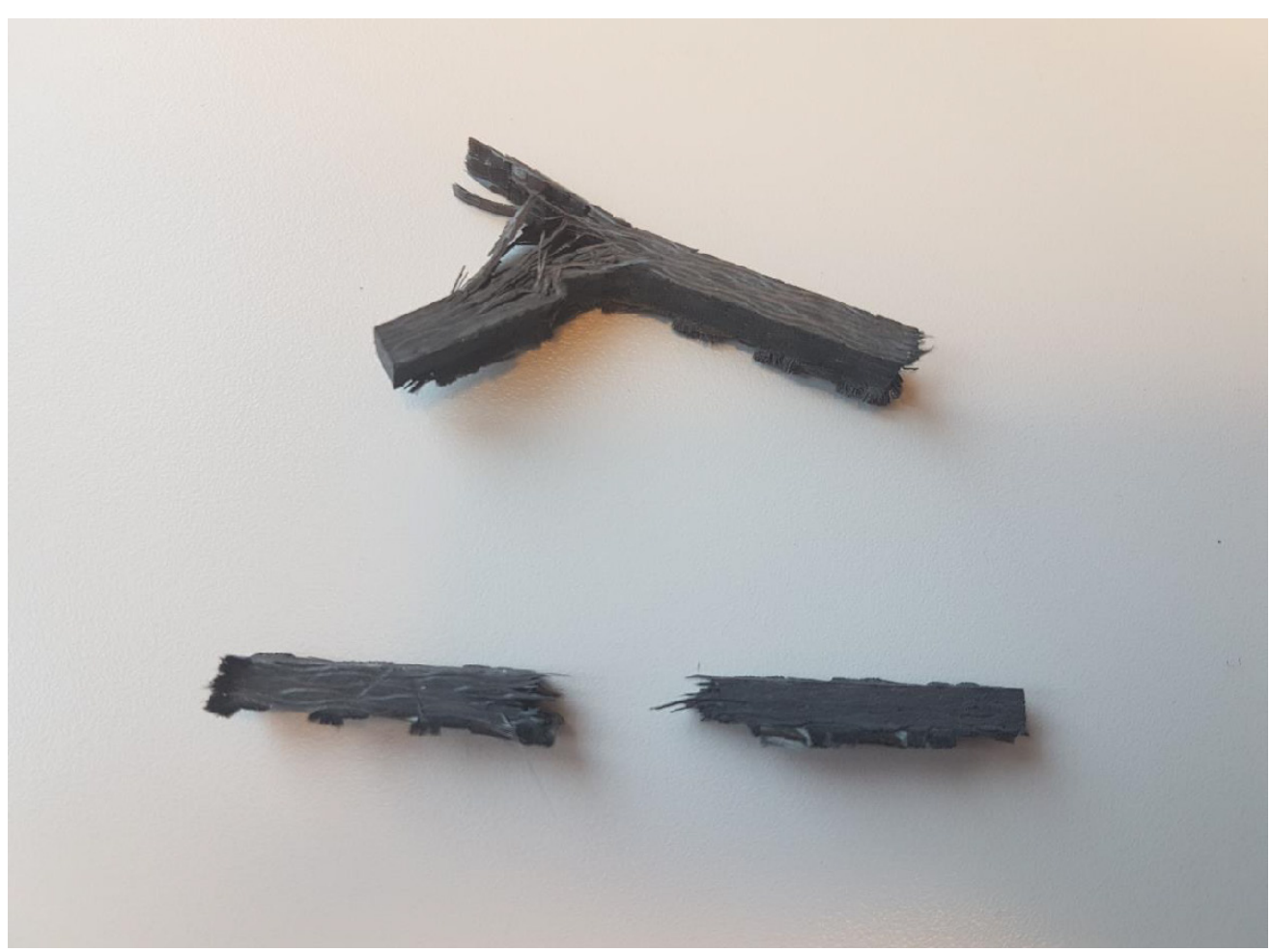

Figure 10: A visual display of the CFRP failure after Charpy experimental test. 
3.2. Numerical Analysis

The simulated Charpy tests of CFRP woven composite material in the explicit dynamics' analysis are presented in Figure 11. The test specimen exhibited an approximately equal deformation behavior as of that observed from the physical experiments.

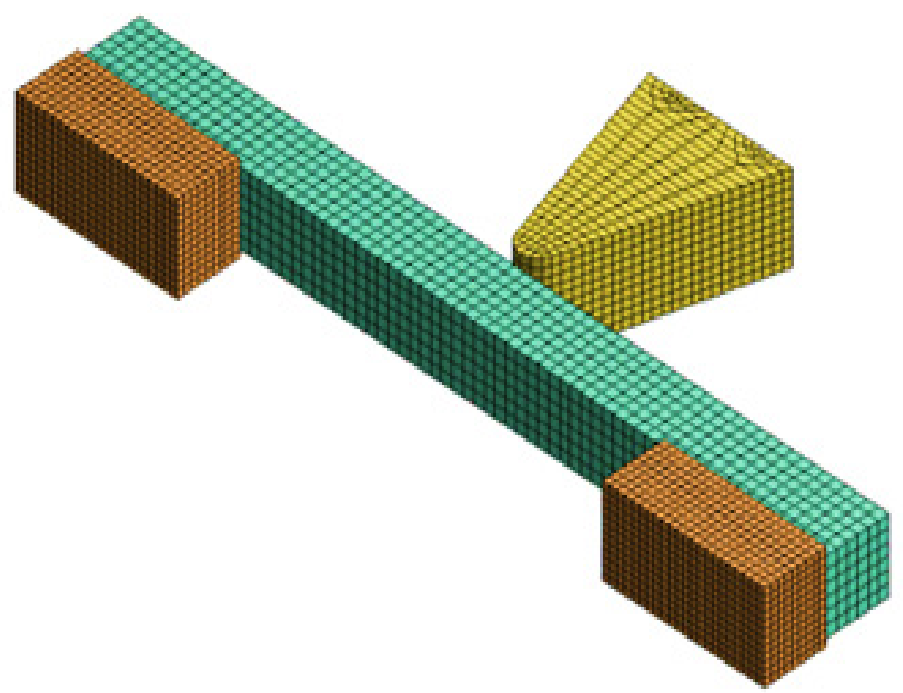

(a)

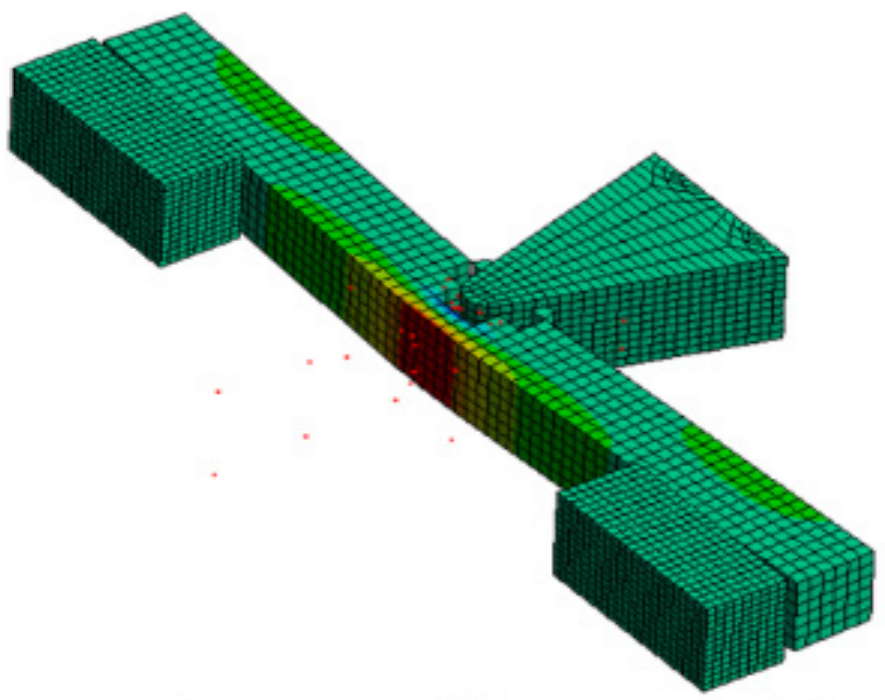

(b) 


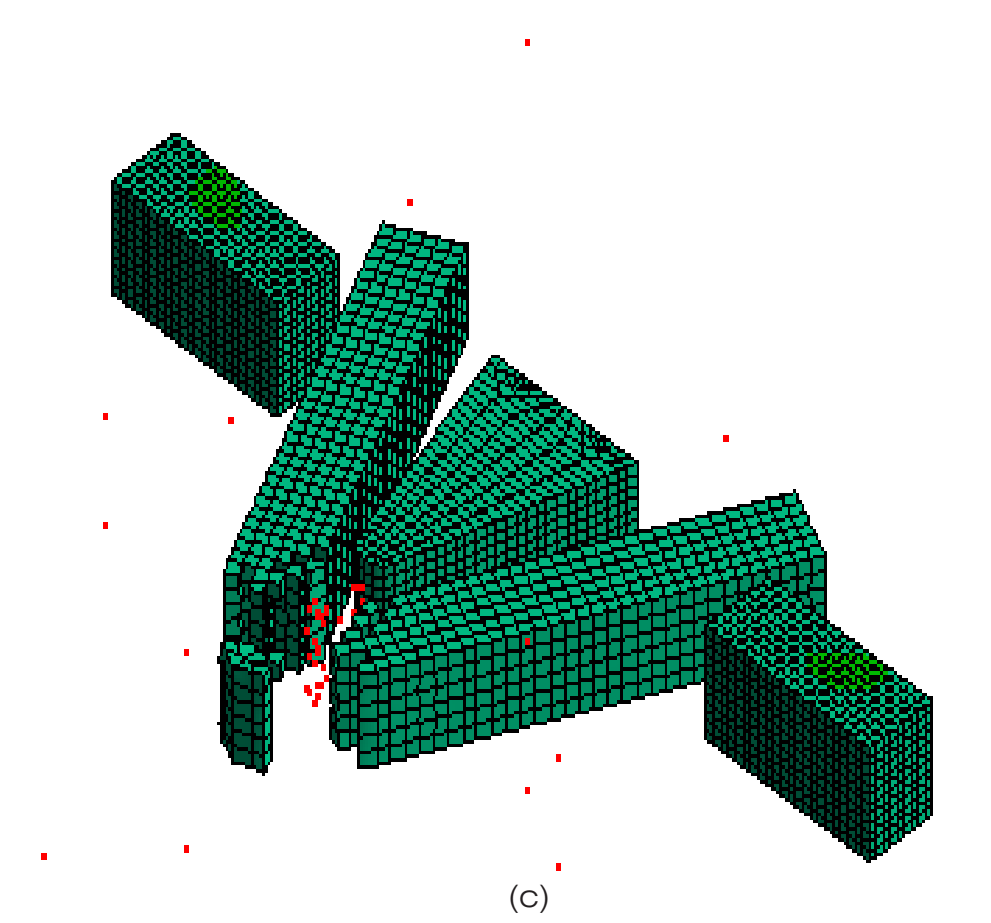

Figure 11: CFRP woven composite Charpy test simulations.

Final velocities that were recorded are given in Table 8 . The directional velocities' curves for room and cold temperature simulations are shown in Figure 12. It was noted that velocities recorded from the simulations were in close agreement to the velocities obtained from the experiments.

Table 8: Velocity results of Charpy hammer edge from ANSYS $®$ simulations.

Initial velocity of Charpy $\quad$ Final average velocity of hammer edge $(\mathrm{m} / \mathrm{s}) \quad$ Charpy hammer edge $(\mathrm{m} / \mathrm{s})$

\begin{tabular}{lcc}
\hline Room Temperature $\left(22^{\circ} \mathrm{C}\right)$ & 3.87 & 2.97 \\
Cold Temperature $\left(-20^{\circ} \mathrm{C}\right)$ & 3.87 & 3.11 \\
Velocity difference & & -0.14 \\
\hline
\end{tabular}

From the velocity versus time curves that were obtained from simulations, it was observed until 5.5E-03 seconds the velocity drop of Charpy hammer was almost similar for both curves. However after $5.5 \mathrm{E}-03$ seconds Charpy hammer velocity dropped to $3.11 \mathrm{~m} / \mathrm{s}$ in cold temperature $\left(-20^{\circ} \mathrm{C}\right)$ before stabilizing where as in room temperature this velocity drop was more pronounced up to $2.97 \mathrm{~m} / \mathrm{s}$ due to ductile behavior of CFRP that enables the material to absorb more energy prior to complete failure. 


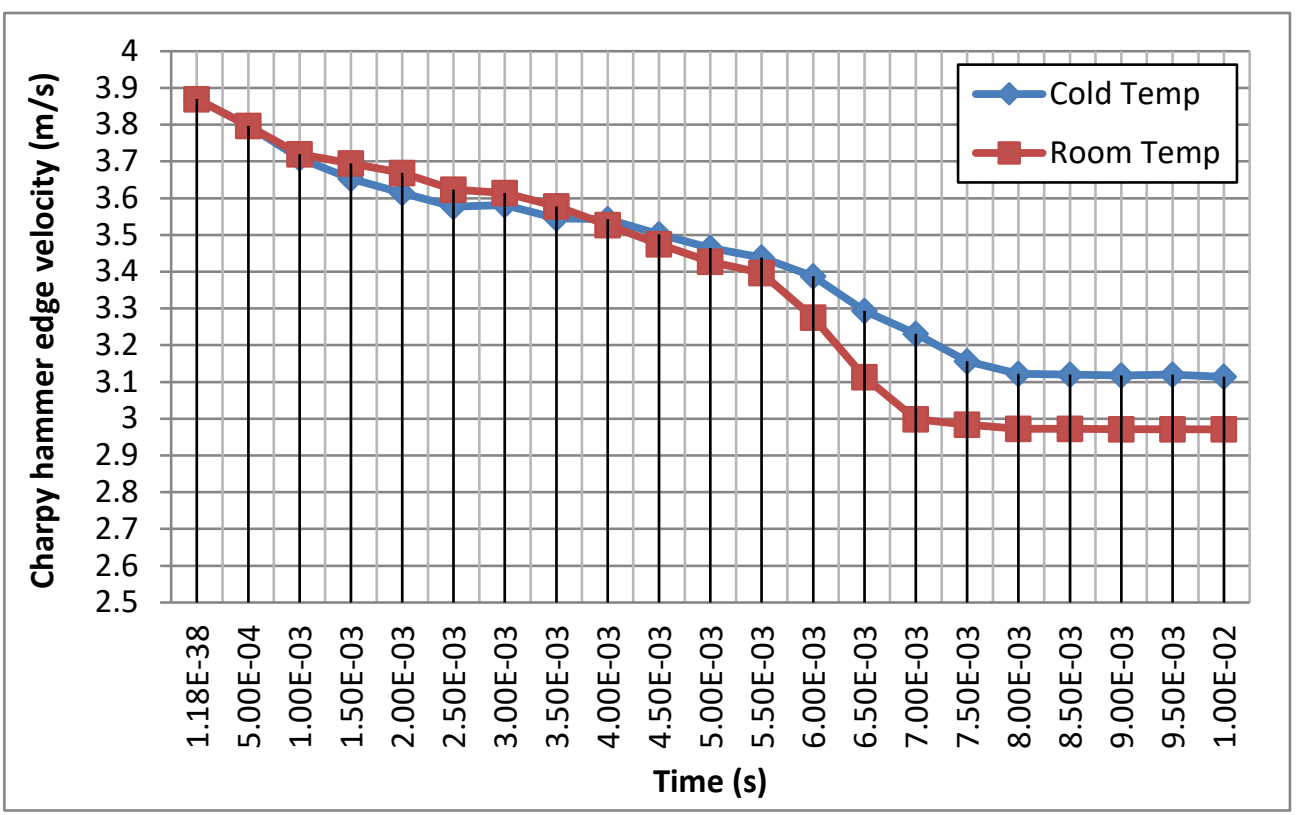

Figure 12: Velocity vs time curves of Charpy hammer edge for room temperature $\left(22^{\circ} \mathrm{C}\right)$ and cold temperature $\left(-20^{\circ} \mathrm{C}\right)$ from $A N S Y S \otimes$ simulations.

Orthotropic elasticity values (stiffness values) that gave the same velocities as obtained from the experimental results were obtained from the ANSYS ${ }^{\circledR}$ simulation as shown in Table 9. These Orthotropic elasticity values were compared with the analytical solution that was obtained by using the rule and inverse rule of mixtures. Upon comparison as shown in Table 10 , numerical values were found to be in good agreement with the analytical solution.

Table 9: Calculated values of orthotropic stiffness values from ANSYS $®$ simulations.

\begin{tabular}{lcc}
\hline & $\begin{array}{c}\boldsymbol{E}_{\mathbf{1}}=\boldsymbol{E}_{\mathbf{2}} \\
\text { for single ply (GPa) }\end{array}$ & $\begin{array}{c}\boldsymbol{E}_{\mathbf{3}} \\
\text { for single ply (GPa) }\end{array}$ \\
\hline Room Temperature $\left(22^{\circ} \mathrm{C}\right)$ & 59.034 & 6.35 \\
Cold Temperature $\left(-20^{\circ} \mathrm{C}\right)$ & 59.40 & 7.04 \\
\hline
\end{tabular}

To analyze the energy drop, of the Charpy hammer edge from ANSYS ${ }^{\circledR}$ simulation study, kinetic energy values were obtained as shown in Table 11. Kinetic energy drop, and percentage of energy difference was calculated (Table 11). From simulation energy results, CFRP samples absorb 9.5 percent less energy in cold temperature $\left(-20^{\circ} \mathrm{C}\right)$ as compared to room temperature $\left(22^{\circ} \mathrm{C}\right)$. In addition, the experimental and numerical results were well aligned that proves the authenticity of the numerical study. 
Table 10: Comparison between analytical and ANSYS $®$ simulation orthotropic stiffness values.

\begin{tabular}{lccc}
\hline Room Temperature $\left(\mathbf{2 2}^{\circ} \mathbf{C}\right)$ & Analytical & Numerical & Difference \\
\hline$E_{1}=E_{2}$ for single ply $(\mathrm{GPa})$ & 59.024 & 59.034 & 0.01 \\
$E_{3}$ for single ply $(\mathrm{GPa})$ & 6.30 & 6.35 & 0.05 \\
\hline Cold Temperature $\left(-\mathbf{2 0}^{\circ} \mathbf{C}\right)$ & Analytical & Numerical & Difference \\
\hline$E_{1}=E_{2}$ for single ply $(\mathrm{GPa})$ & 59.334 & 59.40 & 0.066 \\
$E_{3}$ for single ply $(\mathrm{GPa})$ & 7.01 & 7.04 & 0.03 \\
\hline
\end{tabular}

Table 11: ANSYS® simulation kinetic energy (K.E.) results.

\begin{tabular}{lccc}
\hline & $\begin{array}{c}\text { Initial K.E. of } \\
\text { Charpy hammer } \\
\text { edge (J) }\end{array}$ & $\begin{array}{c}\text { Final K.E. of } \\
\text { Charpy hammer } \\
\text { edge (J) }\end{array}$ & $\begin{array}{c}\text { Loss K.E. of } \\
\text { Charpy hammer } \\
\text { edge (J) }\end{array}$ \\
\hline Room Temperature $\left(22^{\circ} \mathrm{C}\right)$ & 14.6 & 8.71 & 5.89 \\
Cold Temperature $\left(-20^{\circ} \mathrm{C}\right)$ & 14.6 & 9.27 & 5.33 \\
Difference & & & $-9.5 \%$ \\
\hline
\end{tabular}

\section{CONCLUSION}

From the Charpy impact test, it was found that exposure to cold temperature $\left(-20^{\circ} \mathrm{C}\right)$ reduces the energy absorption capability of CFRP woven samples by about $10 \%$. It is reasonable to account that at low temperatures CFRP samples become less tough (brittle) as the area under the stress strain curve reduces significantly. ANSYS ${ }^{\circledR}$ dynamic model successfully validated drop in toughness of CFRP woven samples at low temperature. Hence, at low temperatures stiffness values (Young's Moduli) increases as successfully validated from ANSYS ${ }^{\circ}$ simulations results.

Based on the Charpy impact test and numerical analysis (performed by using ANSYS ${ }^{\circledR}$ Explicit Dynamic software) conclusion was drawn that at low temperatures CFRP woven samples tend to become stiff and fractures with less energy absorption. Such results provide useful insight while designing components from CFRP woven materials to function in cold environments.

\section{REFERENCES}

[1] Hong, S. W. et al. 2013, Charpy Impact Fracture Characteristics of CFRP Composite Materials According to Variations of Fiber Array Direction and Temperature, International Journal Of Precision Engineering And Manufacturing, Vol. 14: No. 2, p. 253-258, Springer New York.

[2] Khawaja, H., Moatamedi, M., Selection of High Performance Alloy for Gas Turbine Blade Using Multiphysics Analysis. 2016, 8(1), pp. 91-100.

[3] Roylance, D., Mechanical properties of materials, 2008, accessed on 1.2.2020, http://web.mit.edu/course/3/3.225/book.pdf

[4] Dutta, P.K., 1988, Behavior of materials at cold regions temperatures Part 1: Program rationale and test plan, 1988, US Army Corps of Engineers Cold Regions Research \& Engineering Lab.

[5] Strand, C., Andleeb, Z., Khawaja, H., Moatamedi, M. Multiphysics Impact Analysis of Carbon Fiber Reinforced Polymer (CFRP) Shell. Materials Science Forum, 2019, 13, pp. $115-120$. 
[6] Khawaja, H., Moatamedi, M. Multiphysics Investigation of Composite Shell Structures Subjected to Water Shock Wave Impact in Petroleum Industry. Materials Science Forum, 2013, 767, pp. 60-67.

[7] Khawaja, H., Kapaya, J., Moatamedi, M. Shock Tube; Detail overview of equipment and instruments in the shock tube experimental setup. Lambert Academic Publishing, 2015, ISBN 978-3-8473-3876-5.

[8] WU, W et al. Dynamic Mechanical Properties of Typical CFRP Laminate Under Highimpact Compressive Loads. The International Journal of Multiphysics, 2018, 12(1), pp.57-78.

[9] Khawaja, H., Bertelsen, T. A., Andreassen, R., Moatamedi, M. Study of CRFP Shell Structures under Dynamic Loading in Shock Tube Setup. Journal of Structures, 2014, 487809.

[10]Khawaja, H., Messahel, R., Souli, M., Al-Bahkali, E., Moatamedi, M. Fluid solid interaction simulation of CFRP shell structure. Mathematics in Engineering, Science and Aerospace (MESA) 2017, 8(3), pp. 311 - 324.

[11]Khawaja, H. A., Messahel, R., Ewan, B., Mhamed, S., and Moatamedi, M, Experimental and Numerical Study of Pressure in a Shock Tube. Journal of Pressure Vessel Technology-Transactions of the ASME, 2016, 138(4): p. 041301.

[12] Arora, $\mathrm{H}$ et al. Modelling the behaviour of composite sandwich structures when subject to air-blast loading. The International Journal of Multiphysics, 2016, 6(3), pp. 197-217, ISSN 2048-3961.

[13] Tanguy, B., Besson, J., Piques, R., Pineau, A. Ductile to brittle transition of an A508 steel characterized by Charpy impact test: Part I: Experimental results. Engineering Fracture Mechanics. 2005 Jan 1; 72(1), pp.49-72.

[14] Tronskar, J. P., Mannan, M A., Lai, MO. Measurement of fracture initiation toughness and crack resistance in instrumented Charpy impact testing. Engineering Fracture Mechanics. 2002 Feb 1; 69(3), pp. 321-38.

[15] Toshiro, K., Isamu, Y., Mitsuo, N. Evaluation of dynamic fracture toughness parameters by instrumented Charpy impact test. Engineering Fracture Mechanics. 1986, 1; 24(5):773-82.

[16] Tanks, J., S. Sharp, and D. Harris. 2016, Charpy impact testing to assess the quality and durability of unidirectional CFRP rods. Polymer Testing, 2016, 51, pp. 63-68.

[17] Dahmen, K.A., Ben-Zion, Y., Uhl, JT. Micromechanical model for deformation in solids with universal predictions for stress-strain curves and slip avalanches. Physical review letters. 2009, 102(17):175501.

[18] Wong, CP., Bollampally, RS. Thermal conductivity, elastic modulus, and coefficient of thermal expansion of polymer composites filled with ceramic particles for electronic packaging. Journal of applied polymer science, 1999, 74(14): 3396-403.

[19] Stange, E., Andleeb, Z., Khawaja, H. Qualitative visualization of the development of stresses through infrared thermography. Vestnik of MSTU (Вестник МГТУ), 2019, 22(4): pp. 503-507.

[20] Stange, E., Andleeb, Z., Khawaja, H., Moatamedi, M. Multiphysics Study of Tensile Testing using Infrared thermography. The International Journal of Multiphysics, 2019, 13(2): pp. $191-202$. 
[21] Khawaja, H. Application of a 2-D approximation technique for solving stress analyses problem in FEM. The International Journal of Multiphysics, 2015, 9(4), pp. 317 - 324.

[22] Gibson, R. F. 2016, Principles of Composite Material Mechanics, Fourth Edition, McGraw-Hill.

[23] Xue, H., Khawaja, H. Analytical and Case Studies of a Sandwich Structure using Euler Bernoulli Beam Equation. Mathematics in Engineering, Science and Aerospace (MESA), 2016, 7(4), pp. 599 - 612.

[24]Brown, M W., Miller, K J. A theory for fatigue failure under multiaxial stress-strain conditions. Proceedings of the Institution of Mechanical Engineers, 1973, 187(1), pp. 745-755.

[25] Explicit dynamics, 2019, ANSYS, accessed on 1.2.2020, https://www.ansys.com//media/ansys/corporate/resourcelibrary/brochure/ansys-explicit-dynamics-brochure140.pdf

[26]ANSYS Workbench User's Guide, ANSYS, Inc., 2019

[27] Engineering simulation platform, ANSYS, accessed on 1.2.2020, https://www.ansys.com/products/Platform

[28] Allred and Associates Inc - Company, accessed on 1.2.2020, http://dragonplate.com/sections/company.asp

[29] Allred and Associates Inc - Product, accessed on 1.2.2020, http://dragonplate.com/ecart/product.asp?pID $=5749 \& \mathrm{cID}=201$

[30]Bader, M. G., R.M.E. 1974, The effect of notches and specimen geometry on the pendulum impact strength of uniaxial CFRP. Composites, pp. 253-258. 